\title{
Stacking practices of high density tailings
}

\author{
Xiaobo Chen Barun Mining Company, China \\ Changlu Yan Barun Mining Company, China \\ Hongnan Yu PSEl International Company, China
}

\begin{abstract}
In Baogang Ba'run Mining Company, the use of high density tailings disposal technology increases the underflow density to 69 71\%cw after two stages of thickening. This process makes full of deep cone thickener and increases the slurry concentration by adding flocculants during thickening, so as to meet the water-saving requirements for the construction of a safe tailings storage facility.
\end{abstract}

\section{Introduction}

Recently, with the highly frequent presence of disadvantages and safety problems caused by conventional tailings pond, more attention has been given to tailings disposal. As an emerging technology, the disposal of high density tailings has become increasingly popular in mining industry and is developing continuously.

Established in the year 2004, Baogang Ba'run Mining Company is located in the north of Baotou where the winter temperature could reach $-35^{\circ} \mathrm{C}$. The engineering design of beneficiation was launched in 2007 and put into trial production in January, 2010. The design of high density tailings disposal project began in April, 2008 and the construction started in June, 2009. In 2010, the primary thickening of the tailings was initiated synchronously with that of the beneficiation engineering and was then officially put into production. The secondary thickening was started in August, 2010.

The disposal project of high density tailings was designed by PSEI which invested a total of 248 million RMB Yuan. Designed to handling 7 million tons of dry tailings per year, the project has a design service life of 14 years for the tailings embankment. After two stages of thickening, the final design concentration of the tailings for discharging is over $70 \%$.

\section{Operation practices of primary thickening}

\subsection{Introduction of primary thickening process}

The primary thickening system is located $150 \mathrm{~m}$ to the south of the beneficiation plant. The feeding slurry has a density of $9.54 \%$ and is thickened to the concentrations between 45 and $55 \%$ (the design concentration is $45 \%$ ) by a high rate thickener. The actual unit flux capacity of the thickener is $13 \mathrm{t} / \mathrm{m}^{2}$ per day (the daily design value is $11.6 \mathrm{t} / \mathrm{m}^{2}$ ). Through slurry pumps, the thickened tailings are pumped into the secondary thickener where their settling process gets accelerated by the addition of flocculants.

\subsection{Primary thickened tailings pump station}

The underflow pump station of the primary thickening system is equipped with two slurry pumps (300zJ-IA90) which pump the tailings slurry from the primary to the secondary thickening area. The pumping flowrate is 1100 to $1200 \mathrm{~m}^{3} / \mathrm{h}$, with an operation pressure of $700 \sim 800 \mathrm{kPa}$. The design concentration of the underflow 
slurry is 45 to $55 \%$ while the current actual value is 49 to $55 \%$. So far, no system failures such as pipeline blockage, pump overpressure and so on have occurred. All the valves are also in good operation.

At the initial operation stage, the underflow pumps were plugged for a few times due to the remained construction waste and the debris that fell into the open-air thickener, disrupting normal production. However, no blockage has occurred since the second half of 2010.

\subsection{The primary thickener}

For the primary thickening, a high rate thickener with a diameter of $48 \mathrm{~m}$ is used that was designed to handling 875 tons of dry tailings per hour. In actual operation, however, it has reached a handling capacity of up to $1000 \mathrm{t} / \mathrm{h}$. The rake-drive torque was found to be below $5 \%$, and no rake arm rise occurred due to over torqueing. In production, the continuous and smooth operation of the thickener mostly depends on the conditions of the wear parts. During the one year of operation, the thickener has disclosed some wear problems such as the leakage of feeding pipe and severe abrasion of the feedwell, hence posing higher requirements for the mechanism materials of the thickener. Furthermore, the thickener operation becomes more challenging in harsh winter climate where the addition of grease lubricant to maintain the continuous its operation becomes increasingly difficult under the ambient temperature of $-30^{\circ} \mathrm{C}$.

\subsection{Flocculant system of the primary thickening}

In primary thickening, flocculant was added to accelerate the settling of solids. The designed adding dosage of flocculant was less than $30 \mathrm{~g} / \mathrm{t}$, and the actual dosage applied was $16 \mathrm{~g} / \mathrm{t}$ in summer time and $20 \mathrm{~g} / \mathrm{t}$ in winter time, with which the thickening system maintained a stable operation with an overflow TSS (total suspended solids) of less than $150 \mathrm{ppm}$ (which met the design requirement of below $200 \mathrm{ppm}$ ). Dilution water was used when adding the flocculant to achieve a desirable flocculation. Currently, a total of 11 flocculant dosing pipes are used, three of which are at the feeding pipe ends and the remaining eight are for adding flocculant to the feedwell.

During over one year's operation, the variation of feed conditions from the upstream process as well as the instability of flocculant dosing control lowers the thickener overflow clarity and results in poor water quality and repeated cleansing of recirculation water pond Meanwhile, under the temperature of $-30^{\circ} \mathrm{C}$ in winter time, preventing the flocculant dosing pipes from getting frozen becomes rather demanding. If the pipes are not insulated properly or the flocculant system fails to function well, the dosing pipes may get frozen and the whole system might shut down as well.

\section{Operation practices of the secondary thickening system}

\subsection{Introduction of secondary thickening process}

Two deep cone thickeners ( $20 \mathrm{~m}$ in diameter and $18 \mathrm{~m}$ in height) were used (one in operation and the other stand-by) for the secondary thickening. The flocculant was also added to accelerate the settling of solids. The underflow had a design concentration of $73 \%$ and pumped by three positive displacement (PD) pumps (two in operation and one stand by) and through a pipeline to the tailing storage facilities (TSF). At the initial stage, the thickened tailings was discharged from the top of the north embankment and flowed towards south (the downstream) within the TSF area. The longest transporting distance designed was $6 \mathrm{~km}$, with the discharge pressure of the mainline pumps being $8 \mathrm{MPa}$.

\subsection{The secondary thickener}

For the smooth operation of the deep cone thickener, the underflow concentration was affected by some key controls, including the operating rate of the thickener, the settled bed, flocculant dosage, dilution water volume, outlet slurry flowrate of the feeding pumps, and etc. Currently, the thickening system can produce 
a consistent underflow density of 69 to $71 \%$ and is still under commissioning to meet the design density requirement of over $73 \%$.

Control of settled bed: at the start-up and commissioning stages, a considerable number of tests were performed to identify the proper height for the settled bed in the thickener in order for the production of high density underflow. No previous experiences could be referred to since this is the first high density tailings disposal project in China. Comparisons were drawn among the test results of bed levels varying from 11 to $17 \mathrm{~m}$, and the following conclusion was obtained. Within such a bed level range, while the bed height had no obvious impact on the underflow density (which only raised by $1.5 \%$ when the bed level increased from 11 to $17 \mathrm{~m}$ ), $\mathrm{t}$ the overflow water quality is more likely to deteriorate. Currently, the bed height is controlled within 13 to $14 \mathrm{~m}$ and the system operates in a good condition. The design underflow density is $65 \sim 68 \%$.

Table 1 Underflow density versus settled bed height

\begin{tabular}{cccc}
\hline Bed height (m) & Tank pressure (kpa) & Underflow density (\%) & Rake torque (\%) \\
\hline 11 & 370 & 68.5 & 16 \\
12 & 385 & 68.5 & 16 \\
13 & 398 & 69.3 & 18 \\
14 & 410 & 69.8 & 20 \\
15 & 412 & 70.1 & 22 \\
16 & 416 & 70.1 & 25 \\
17 & 420 & 70.4 & 30 \\
\hline
\end{tabular}

Control of operating speed: the operating speed of rake arms is determined by that of the thickener and in turn determines the discharging rate of the water from the settled bed. Higher operating speed of the thickener leads to higher operating speed of rake arms, which increases the water volume discharged out of the settled bed through the water diversion pipe and also increases the rake torque and the rotation of the settled bed. After the thickener had operated at the motor's full speed of $50 \mathrm{~Hz}$ for a certain period, the underflow density had no obvious rise. Therefore, for the purpose of smooth operation, the thickener was set to operate at the speed of $30 \mathrm{~Hz}$ (of the motor).

\subsection{Flocculant system of the secondary thickening}

In the flocculant adding system of the secondary thickening, a flocculant preparation unit was used, which includes a $30 \mathrm{~m}^{3}$ preparation tank and a $60 \mathrm{~m}^{3}$ storage tank so as avoid the problems caused by poorly dissolved flocculant similar to what occurred in the primary thickening system. The flocculant dose rate was set at $<30 \mathrm{~g} / \mathrm{t}$ (i.e. less than 30 grams of flocculant per ton of solids feed). Currently, $a<20 \mathrm{~g} / \mathrm{t}$ dose rate is used and the overflow TSS is less than 200 ppm.

Table 2 Flocculant dosing rate versus thickening effect

\begin{tabular}{cccc}
\hline Flocculant dosing rate $(\mathbf{g} / \mathbf{t})$ & Thickener operating speed $\mathbf{( H z )}$ & Rake torque (\%) & Underflow density (\%) \\
\hline 15 & 25 & 31 & 68.5 \\
20 & 25 & 28 & 70.1 \\
25 & 25 & 25 & 69.4 \\
30 & 25 & 21 & 68.3 \\
\hline
\end{tabular}

A proper dosage of different types of flocculants is vital for the increase of underflow density. Over-dosage does not necessarily lead to expected thickening effects and too low a dosage cannot achieve flocculation, either. Therefore, for different types of flocculants, a rational dosage control is essential to the thickening process.

Control of flocculant dilution water: dilution water is a necessary process condition for the flocculant dosage 
and important for the flocculation effect. A rational dilution water feed will help ensure that the flocculant achieves the desirable flocculation effects, hence improving quality of the overflow and low underflow density. In the current operation, the dilution water feed volume is $100 \mathrm{~m}^{3}$, with which the flocculant can be diluted to 10 times the volume before being added to the system and achieve a satisfactory flocculation effect.

\subsection{Charge pumps (underflow pumps) of the secondary thickening}

Currently the designed PD pumps are not in use because of the short discharging distance and that the underflow density has not yet met the design requirements. The underflow can be directly pumped by the pumps to the TSF for storage. During the operation, the flow rate of the charge pumps was maintained within $700 \sim 900 \mathrm{~m}^{3} / \mathrm{h}$, with their outlet pressure within $300 \sim 400 \mathrm{kpa}$. The control of the outlet flow rate o directly affects the control of the underflow density. The balance between the underflow discharge and the feed of the thickener is the precondition for the controlling of a consistent settled bed, thereby achieving a steady increase of the underflow density.

Currently, the flow control of the charge pumps is far from being effective. Due to the fluid level in the thickener itself and the short discharging distance, the underflow pumps can achieve a flow rate of $700 \mathrm{~m}^{3} / \mathrm{h}$ even without starting up, making the maintenance of the solids settled bed difficulty. For now, the pinch valves used to control the discharge flow, however, fail to bring an ideal controllable flow range, and also make the abrasion of the valves more severe.

\subsection{Return water flushing system}

The overflow with a velocity of approximately $7000 \mathrm{~m}^{3} / \mathrm{h}$ from the primary thickener was diverted directly to the recirculation water pond for reuse. For the overflow water return of the secondary thickening system, the water first flowed into an overflow tank and was then pumped by three return water pumps (two in operation and 1 standby) into the recirculation pond in the beneficiation plant. The design flow of return water was $800 \mathrm{~m}^{3} / \mathrm{h}$. Currently the total return water flowrate is $700 \sim 800 \mathrm{~m}^{3} / \mathrm{h}$, of which $500 \sim 600 \mathrm{~m}^{3}$ is from the overflow of the secondary thickener and $200 \mathrm{~m}^{3}$ from the water collection pond in the TSF.

The primary and secondary thickening system each has a separately designed flushing water system which uses the return water to flush the underflow piping and slurry pipeline so as to prevent piping blockage as well as to ensure the smooth valve operation.

\section{$4 \quad$ Tailings Storage Facilities (TSF)}

\subsection{General layout}

The tailings embankment was constructed surrounding the tailings disposal site using waste rocks. The north embankment is used as the main discharging place, with the west embankment used as the temporary discharging place when the former fails to work and during the construction stage. Meanwhile, another tailing pond is used as the emergency discharging site for situations where the secondary thickening system or TSF fails so as to ensure a normal operation of the whole beneficiation system. Throughout the whole area of TSF laid a flood discharging culvert made of prefabricated concrete pipes so as to discharge the flood from the upstream private beneficiation plants. A water collection pond was constructed the downstream of TSF to collect the tailings bleed water and rainwater within the TSF area.

\subsection{Operation comparison of TSF in winter and summer time}

In winter, due to the continuous low temperature in the local area, the deposition of high density tailings is more difficult compared to that in the summer.

Slurry flow regime: 
- In summer: the tailings slurry flows along the terrain and forms a tailings beach where the slurry deposits layer by layer.

- In winter: the tailings slurry flows along the terrain and forms a ditch until the south embankment. The freezing of both sides of the flow prevents the formation of tailings beach.

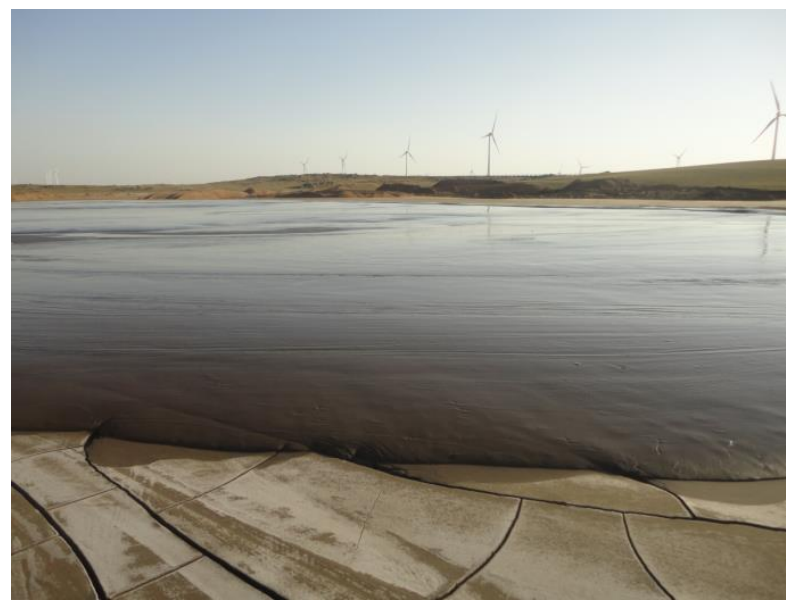

\section{Figure 1 Tailings deposition state in summer}

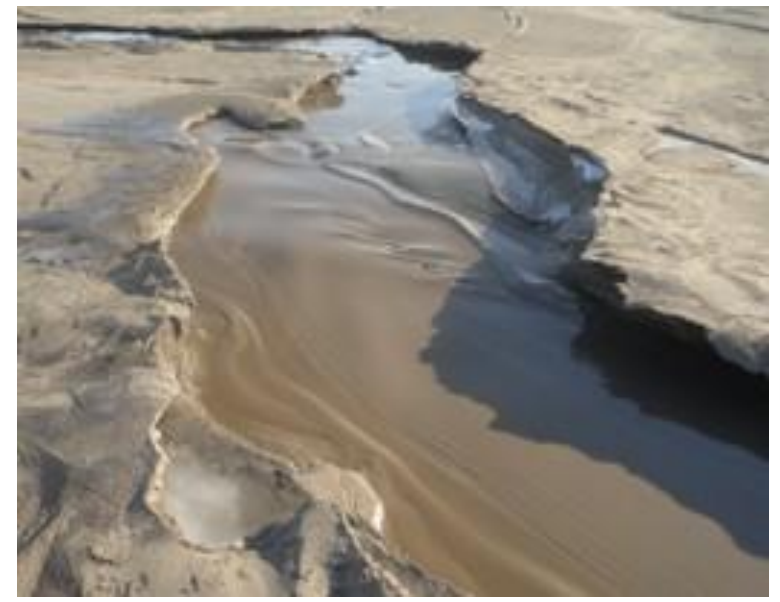

Figure 2 Tailings deposition state in winter

The dust:

- In summer: the formation of tailings beach avoids the generation of dust.

- In winter: with no tailings beach formed, the slurry could not deposit layer by layer, hence generating dust locally within the TSF area.

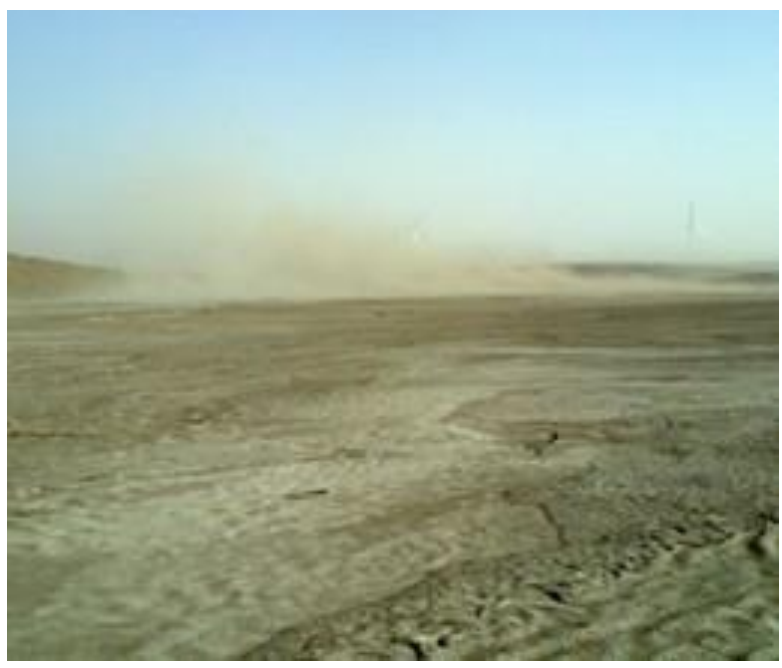

Figure 3 Tailings deposition area in winter 


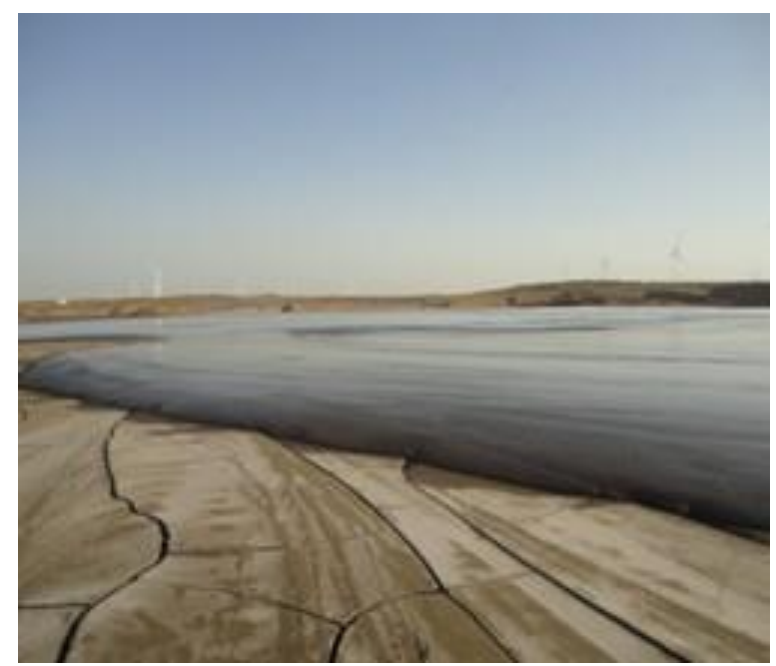

\section{Figure 4 Tailings beach in the summer}

State of the water collection pond:

- In summer: the formation of tailings beach is conducive for the tailings deposition. The clear water with rather good quality collected on the north of the south embankment flowed into the water collection pond through a water intake chute.

- In winter: the slurry flowed along the terrain to the south embankment without complete deposition. The un-deposited tailings flowed into the water collection pond through the water intake chute, seriously affecting the water quality in the water collection pond and also likely to cause blockage in the water intake facilities.

Currently, improvement has been achieved for the tailings discharging method in the winter time, i.e. discharging from multiple points, which is very effective for the tailings deposition and dust control.

\section{$5 \quad$ Process Indices}

The process indices that have been achieved so far are as below: 1) Under the concentration of $70 \%$, the tailings slurry is of good fluidity and no shear pump is needed. 2) The flocculant dosage is controlled at $20 \mathrm{~g} / \mathrm{t}$ (the design value is $30 \mathrm{~g} / \mathrm{t}$ ) and the overflow TSS is lower than $100 \mathrm{ppm}$ (the design requirement is less than $200 \mathrm{ppm}$ ). 3) All the major equipment and ancillary facilities are in normal operation.

Current working efforts include: 1) adjusting the configurations of the deep cone thickener and modifying the rake structure and layout of the water divert pipes to achieve the underflow concentration of over $73 \%$; 2) introducing the new type of flocculant and optimize its adding method to reduce the dosage to the maximum extent; 3 ) furthering the study of the relationship between the underflow concentration and the height of solids settled bed in the thickener; 4) studying the relationship between the feed slurry concentration and the underflow concentration; 5) figuring out the relationship between the underflow concentration and the retention time of slurry in the thickener; 6) studying the discharging methods of high density tailings and discharging concentration in different seasons; 7) Studying the flow regime of the high density tailings and improving the embankment layout, to fully use the TSF volume.

\section{Summary}

The achievement of a high density tailings firstly depends on the rational sizing of the thickener and selection of a proper process, made possible by the use of the deep cone thickener. Meanwhile, it is also proved that, for the deep cone thickener, the higher solids settled bed does not necessarily lead to the higher density of underflow, but instead easily causing the overflow off-specification and even a production failure. 
The addition of flocculant in thickening increases the concentration and water quality of the overflow, while reducing the rake torque of the thickener and ensuring its smooth operation. In addition, a rational dosage of flocculant is the precondition for achieving the high density of the underflow.

In cold weather, the operation of the high density tailings storage facilities is challenged by the non-formation of beach and dust generation. Meanwhile, the bleed water quality of the slurry could not be guaranteed, thus affecting the quality of the return water. However, the above situation has been improved greatly after the multiple points discharging method was introduced.

\section{Bibiography}

Modern iron ore processing, University of Science and Technology of China, 2009, ISBN 978-7-312-02596-9. 